\title{
An Educational Approach to the Art of Living
}

This is the pre-published version of an article that has been published in Knowledge Cultures. Please use this reference for quoting this article:

Teschers, C. (2013). An Educational Approach to the Art of Living. Knowledge Cultures, 1(2), pp. 131-144. 


\title{
An Educational Approach to the Art of Living
}

Christoph Teschers

University of Canterbury, New Zealand

\begin{abstract}
This article will engage with theories about the art of living and the good life, especially Schmid's concept "Lebenskunst", as well as with relevant findings of positive psychology research from an educational point of view. An argument will be made for the importance for education to refocus on the lives and living circumstances of our students, and the contribution an art of living can make to education. It will be shown that a shift of the educational focus in theory and practise is necessary, away from being mainly economical driven to a more comprehensive understanding of education and Bildung that includes not only social and economical considerations, but also other important aspects of human life and well-being.
\end{abstract}

\section{Introduction}

Today's societies are mostly characterised by a host of opportunities and challenges alike. The pace of life is quicker than ever before, and the changes and developments in societies, science and technology come about faster every day. The major challenge for human beings is to make a myriad of choices every day, which will define their place in society, in life and in the world altogether. To make prudent and sensible decisions is, therefore, a key competence for a successful and good life. One of the difficulties is to acquire this key competence in time: in a fast moving and changing world, where children's life-experiences are very different from everything their parents encountered; in schools, where curricula are overloaded with facts and scientific knowledge to prepare for an age of knowledge, which doubles on average approximately every three to eight years; and in societies that are globalised and influenced by dozens of cultures from all over the world, the challenge to find - and define - the way one wants to live has reached a scale where people need help to learn the skills and knowledge that are necessary to live a good life. This question of how to live a good life, however, has been discussed in philosophy for thousands of years, and answers have been found in many cultures over the centuries. Nevertheless, as Csikszentmihalyi (2008) points out in his book Flow, the answers today might be the same as discovered in the past, but they need to be rephrased, as people in different cultures and with changing historical background no longer understand the former wisdom. Scholars like Martha Nussbaum (2001), Alexander Nehamas (1998), Fred Feldman (2004), Mihaly Csikszentmihalyi (2008) and Wilhelm Schmid (2000a, 2000b) are only some, who have been interested in formulating an understanding of an art of living for people today.

There are various philosophical approaches to leading a good life. One of them, and the one favoured in this article, is the art of living concept "Lebenskunst" from Schmid (2000a, 
$2000 \mathrm{~b})^{1}$, which he describes as the art of taking up responsibility for one's own life and trying to make it a 'beautiful' one. Schmid does not present this concept as a prescription for how everybody should live, but as a way to enable individuals to find their own way to live a good life from their subjective point of view. At this point, however, one might ask why it is important or necessary at all to add an educational point of view to the art of living, when there are already various philosophical theories. A trivial answer would be that knowing about the art of living and teaching the art of living are very different indeed. Additionally, on a more fundamental level, it might be even controversial if teaching how to live a good life is possible at all. Therefore, a more thorough answer is needed.

Hence, the first question that has to be addressed from an educational perspective is the question if it is possible at all, not only to teach about the art of living, but to teach anything that can help to develop one's own good life and one's own art of living. When this point will have been made, further questions spring to mind: what are the skills and knowledge that can be taught, how can they be taught, which settings suit best, which methods are most beneficial and so forth. The scope of this paper does not allow to discuss all these questions, but to consider them at all, one has to have an underlying idea or concept of the art of living first - a theoretical framework to base one's answers on. Various concepts have been taken into account (see Teschers (2010) and Teschers (2011) for more details) and it will be argued here that Schmid's approach is a good foundation to build on, but also commented on some of its possible shortcomings for educational purposes in the light of other philosophical concepts. Further, a dialogue between philosophical and psychological approaches (Teschers, 2011) will provide significant input for an educational perspective as well.

A second answer to the question of why an educational approach is necessary in the first place, is mainly a combination of the question of the overall importance of the art of living for human beings and society, and of the intention and purpose one attributes to education in general. To approach the first part of this question, one treads on highly philosophical ground: what is the purpose of human life, what are we here for, and is leading a good and beautiful life part of our inherent human plan and purpose? It will become apparent that Schmid's concept of the art of living provides a solid foundation for the outlined questions, as his concept suggest a simple, but not easy idea: there is no such thing as one answer to living a good life, but every human being has to find his or her own answers and shape one's own life accordingly. This will, hopefully, result in a life that this individual can appreciate as a good or beautiful one (see Schmid (2000b, p. 7) or Teschers (2010, p. 1-2)). Therefore, developing one's own art of living, understood in Schmid's terms, bears the answers to these questions of life; hence, engaging in the art of living - conscious or ignorant of its theoretical background - is highly significant for human beings.

Also, from a more pragmatic perspective, Aristotle (I, iv, 2) argues that the utmost good that human beings can achieve is eudaimonia, which can be described as an overall attitude of serene happiness, and that most, if not all, human beings strive to reach eudaimonia.

1Schmid a contemporary German philosopher, whoes work has not been translated into English, yet. See Teschers (2010) for an English summary and discussion of his philosophy. 
Therefore, happiness is a strong motivational factor for human action and decision-making. On the other hand, which actions and decisions lead to serene happiness for an individual is again the field of the art of living. This leaves the question if education should be concerned with the quality and purpose of pupils' lives at all. This will be discussed in the following section.

\section{An End of Education}

In the public as well as in the academic discussion, many ideas about the purpose of education have been voiced, but there is hardly any consensus. The ideas vary from transferring knowledge (sometimes called instruction); over socialisation and reproduction (tradition) of society and culture; to critical thinking and lifelong learning. Education, in fact, includes all those purposes and many more. The historical circumstances, the reality of the current society, and the living environment of the individual determine which objectives are regarded with higher priority and come to the fore (Dewey, 2001, p. 116). The question is if an overall aim for education can be identified at all. Dewey (ibid.) certainly denied the existence of "some one final aim which subordinates all others to itself." However, he identifies three main streams of thoughts that subsume most of the aims people attributed with education in his time: the natural, individual development (Rousseau); socialisation (or social efficiency); and personal mental enrichment (or culture). Although the terms he uses might be slightly misleading if they are read in current social contexts, the underlying concepts are nevertheless still relevant for the present time: the clear single sided emphasis on socialisation and economical benefit in contemporary educational systems, which are often strongly influenced by neoliberal social and political tendencies, produce similar difficulties for democratic societies and the development of human beings as in Dewey's historical circumstances.

Dewey discussed the three general aims of education above and pointed out their strong sides and their weaknesses. He supports some key aspects of the natural development of the individual, as described in Rousseau's Emile:

The three factors of educative development are (a) the native structure of our bodily organs and their functional activities; (b) the uses to which the activities of these organs are put under the influence of other persons; (c) their direct interaction with the environment. This statement certainly covers the ground. His [Rousseau's] other two propositions are equally sound; namely, (a) that only when the three factors of education are consonant and cooperative does adequate development of the individual occur, and (b) that the native activities of the organs, being original, are basic in conceiving consonance. (Dewey, 2001, p. 118)

On the other hand, Dewey (2001, p. 118-119) criticises Rousseau's belief that the three "factors of educative development" are independent from each other, and especially his take that one's organs and natural faculties can develop "irrespective of the use to which they are put." He summarises that Rousseau's critique of the educational practice of his time has 
been righteous by pointing out the importance of the individual nature of each pupil as a fundamental educational condition, but that he was wrong in stressing this point to become the final end of development and sole aim of educational intervention.

On the other hand, Dewey argues that the opposite take of "social efficiency as aim" (2001, p. 123) is evenly flawed, as its supporters often neglect the importance of individual and inter-individual diversity. They also, at least in Dewey's time, often did not take into account the quickly changing environment in industry and the need for flexibility, but instead proclaimed a training "for too specific a mode of efficiency[, which] defeats its own purpose" (2001, p. 125). However, no educational system can afford to neglect the need to train its students in a way that enables them to participate in economy and industry, and to earn their own living. As a second aspect of social efficiency, Dewey names "civic efficiency, or good citizenship" (ibid.), which includes all traits that "run from whatever make[s] an individual a more agreeable companion to citizenship in the political sense" (ibid.). Some of them are, for example, to be able to create and enjoy art; participate in recreation and leisure; and to formulate and abide laws. Finally, Dewey summarises social efficiency as something that is more or less close to the contemporary understanding of socialisation:

It must be borne in mind that ultimately social efficiency means neither more nor less than capacity to share in a give and take of experience. [...] In the broadest sense, social efficiency is nothing less than that socialization of mind which is actively concerned in making experiences more communicable; in breaking down the barriers of social stratification which make individuals impervious to the interests of others. (Dewey, 2001, p. 126)

Moving on to Dewey's considerations about culture, he describes it as "something personal; it is cultivation with respect to appreciation of ideas and art and broad human interests" (2001, p. 127). It is a personal refinement in opposition to the "raw and crude" (2001, p. 126). However, he is pointing out that this personal refinement must not be conceived as something solely "inner":

What is called inner is simply that which does not connect with others - which is not capable of free and full communication. [...] What one is as a person is what one is as associated with others, in a free give and take of intercourse. This transcends both the efficiency which consists in supplying products to others and the culture which is an exclusive refinement and polish. [...] And there is perhaps no better definition of culture than that it is the capacity for constantly expanding the range and accuracy of one's perception of meaning. (Dewey, 2001, p. 128129)

He argues against the opposition of "self-sacrifice" and "spiritual self-perfection", instead he advocates that "it is the particular task of education at the present time to struggle in behalf of an aim in which social efficiency and personal culture are synonyms instead of antagonists" (ibid., my italics). Dewey summarises that partially stated aims, focusing either on the individual's nature, culture or on socialisation, fall short of providing an overall end 
of education, as these aims come into conflict with each other and on their own do not take into account all aspects of educational circumstances in reality. However, combining these aims by recognising

[...] that natural activities mean native activities which develop only through the uses in which they are nurtured, the conflict disappears. Similarly [...] social efficiency as an educational purpose should mean cultivation of power to join freely and fully in shared or common activities. This is impossible without culture, $[. .$.$] because one cannot share in intercourse with others without learning$ - without getting a broader point of view and perceiving things on which one would otherwise be ignorant. (Dewey, 2001, p. 129)

What evolves here is an argument for a holistic approach and an overall aim of education that takes into account the human being with both, its nature and its ability to culture one's mind and form one's character ${ }^{2}$. Dewey (2001, p. 100) proclaims a proper end of education to be "the promotion of the best possible realization of humanity as humanity;" although, this end is hardly pursued in real world situations, as the focus lies often on the short term or immediate benefit and advantage for the students in the present cultural setting ${ }^{3}$.

Hence, an overall aim or end of education, from an art of living perspective and with Dewey's critique in mind, can be formulated as follows:

Based on this aim, education needs to begin with and centre on the pupil; it needs to focus on the subject (individual), not the object (content) of the teaching-learning interaction. Dewey argues for two main stakeholders of education: on the one hand the society, on the other the individual human being. In the light of Schmid's theory of the art of living, the interests of the first are included in the development of the second through the qualities of prudence and practical wisdom, and through the notion of the individual's own best interest. As argued elsewhere (Teschers, 2010, p. 5), an individual with a developed sense of prudence and practical wisdom has to take into account the desires and needs of the people around him or her, and has to act accordingly. Also, one's own self-interest requires the pupil to master the knowledge and skills that allow him or her to live as effortless as possible in the current society, which includes serving its purpose and demands as much as they are in line with one's own norms, beliefs and aims.

As a consequence, the outcome of transferred knowledge and learned skills might not vary much from what is taught in schools today, although some changes in content will be necessary. In manners of proceeding, however, changes are most likely and there will

2Dewey's notion of culture and personal mental enrichment (as discussed on pages 126-129) calls to mind the German concept of Bildung, which will prove to be an important concept for the educational concept proposed later on.

3Compare R. S. Peters (1973), who presents a different position about ends and aims in education, and argues for education as an end in itself. 
certainly be a difference in the pupils' experience of education, and hopefully in their ability to shape their own lives.

\section{The Importance of the Art of Living for Education}

As shown above, the end of education is not (or should not be) in the first place to instruct, or teach young people a profession and the necessities to become a useful and functioning part of the current society, with the main intent of growing and contributing to the countries economy and industry. The aims resulting of the end of educating as discussed above are rather to allow human beings (a) to grow and develop their capabilities; (b) to make sense of the world and the culture they are living in; (c) to reflect on one's own self, one's own beliefs and values; and (d) to flourish in a way that enables them to actively shape their own lives into potentially good and beautiful ones. An in-depth philosophy of the art of living is important to identify which skills and knowledge, as well as teaching methods and settings are necessary or beneficial to achieve these aims.

The contribution Schmid's (2000a; 2000b) theory of Lebenskunst [art of living] can make to the first aim (a) of growth and the development of capabilities becomes apparent in the notion of the prudent care of the self. To be able to grow and form one's own self it is necessary to have some knowledge about oneself in the first place. Knowing oneself includes knowledge about one's own history; one's faculties; and the desires and ideas one has, as these reveal the contents and inter-connections of one's self (Teschers, 2011). The first aspect of Schmid's care of the self concept is to be self-receptive (2000a, p. 246). It is the experience of one's own self as oneself, which belongs not to others but to oneself alone; it is also the awakening of one's own self-interest. The ability to consciously perceive oneself and to be receptive of one's own self is, therefore, the first step educational intervention has to focus on. The subsequent step, according to Schmid, is self-reflection, which will cause a transition from self-perception to self-awareness and is also a fundamental skill for aim (c). The ability to reflect upon oneself can be supported significantly by a guiding educational approach; the new found self-awareness will help the pupil to see one's own life from a distance, which enables him or her to realise one's own circumstances, conditions and opportunities. In a final self-productive step, the pupil will learn how to shape one's own self and one's own life, which concludes, on its highest level, in the realisation of the care of the self and subsequently one's own art of living.

However, the realisation of the art of living is not as simple and straight forward as outlined in the paragraph above; although, the core concept seems indeed not to be overly complicated. The question is, what else is needed to actively shape one's own life in a way that one can experience it as a good and beautiful one. One condition is formulated in aim (b): to make sense of the world and culture one is living in. The second step of the care of the self (self-reflection), as outlined above, can only lead to a realisation of one's own circumstances, conditions and opportunities if one can make sense of what one is seeing and reflecting upon. Schmid's (2000b, p. 286-292) answer to this challenge lies in hermeneutics: hermeneutical skills and knowledge are part of the care of the self, and hermeneutics is in itself the art of finding one's way through life and make sense of what 
one is experiencing in the world. Hermeneutical skills are also required to make informed choices, which has been shown above to be a challenge for people today.

As mentioned above, a key skill for aim (c), the reflection on one's own self, one's beliefs and one's values, is obviously the ability for self-reflection. The pupil needs to learn how to make him or herself the object of one's own reflection. But, although, this skill is necessary, it is not sufficient at all to realise the aim discussed here. To reflect critically on the values and beliefs one is confronted with, in the culture and society one is growing up in, requires a certain kind of knowledge to be able to put these values and beliefs into perspective, and it requires a way of reflection that engages with the external ideas critically. Schmid (2000b, p. 310-317), in this context, employs the concept of Bildung [(self-)cultivation] as the foundation for comprehension and understanding. Bildung, in the German understanding, is more than facts-knowledge alone; it also includes the formation of one's character and a notion of practical wisdom. The way of reflection, mentioned here, can be found, according to Schmid (ibid.), in the notion of cultivating critical thinking.

The final part (d) of the end of education, as described above, is harder to grasp and more difficult to break down into practical educational goals. To flourish and shape one's own life in a way that may result in a good and beautiful one might be as diverse as the number of living human beings. However, to be able to flourish and shape one's own life accordingly might prove to be much less demanding than catering for the diversity, these skills and knowledge might enable to. As argued elsewhere (Teschers, 2010, p. 6), according to Schmid, the care of the self is the core of the art of living. Therefore, the aims (a) to (c) are essential for the individual to approach a flourishing way of living. But Schmid refines his terms further in this context: he refers to the care of the self as "kluge Selbstsorge" [prudent self-care] (2000a, p. 256, my italics). The German term "klug", which is significant for Schmid's philosophy, does have two connotations: prudence and practical wisdom; Schmid continuously refers to both meanings in his philosophy. Hence, prudence and practical wisdom are important qualities, whose development needs to be supported in educational settings. Both terms are also closely related to the concept of Bildung. Further, Schmid (2000b, p. 303-310) emphasises the importance of "Lebenwissen" [life-knowledge], which is an empirical, practical form of life's know-how and not a scientific metaknowledge about life. This kind of life-knowledge needs to accumulate over time, but the development and growth of this knowledge can be supported by educationalists through structured or designed experiences ${ }^{4}$. A condition for flourishing that might stress the limits of education is the freedom every individual needs to be able to make choices and to shape one's own self and one's own life. However, the concept of freedom has different layers, some are internal, others external. The internal boundaries can certainly be stretched through education, which is an inherent function of learning, and it might be possible for the pupil to influence the external constrictions, once the mind has found a way to be free.

4Rousseau's Emile is only one example of designed experience education. More practical examples can be found in outdoor and adventure education. 


\section{Educational Critique of Schmid's concept "Lebenskunst"}

Although it has been discussed earlier (Teschers, 2010) and also indicated above that Schmid's approach to the art of living is a suitable starting point for an educational perspective, there are some critical aspects and limitations from an educational point of view that need to be addressed. Schmid seems to propose a holistic philosophical concept by emphasising the responsibility of the individual to decide upon one's own values and beliefs, and to shape one's own life. Educational processes, however, are always based on a certain selection by the teacher, who is influenced by own and culturally transmitted values and beliefs. Also, an educational approach needs to take into account the different cultural teaching settings and social circumstances in which pupils are to be enabled to develop their own art of living. Schmid does not address these issues in sufficient depth, as his take on the art of living focuses on the individual human being. He acknowledges the social component, but argues that in the end it is up to the individual to decide if he or she wants to embrace the cultural values and settings one is born into and raised with, or not. While this basic assumption is true for all human beings in every culture, as an educationalist one is always restricted by the social norms and cultural circumstances one happens to work under. Although the end of education, as stated above, should be the same, the settings, methods and even contents of the educational intervention will most likely differ. The first challenge here would be to identify groups of methods, settings and contents that indicate the boundaries of significant educational intervention for an individual art of living. Due to the scope of this paper, this will have to be addressed in more detail in subsequent work.

The second issue, pointed out above, is the question of the scope of Bildung that needs to be achieved to enable the pupil to actively shape his or her own life and potentially live a beautiful one. To explore this issue, a deeper understanding of the concept of Bildung will be helpful. As explained above, the term Bildung has three dimensions in the German understanding: knowledge, character formation and practical wisdom. A person with Bildung is a self-cultivated person, who transferred learned knowledge through reflection and contemplation into shaping one's own character and acquiring practical wisdom. This self-cultivating process can be supported and guided by a mentor or teacher: for example, through asking critical questions and encouraging the pupil's thinking process. But how much knowledge needs to be acquired? How much cultivation is necessary for an art of living? An answer to these questions cannot be absolute, as they are tightly linked with the cultural and social setting; the individual's innate and developed skills and faculties; and, subsequently, the content of knowledge, as discussed above. However, as will be shown later on, the content of significant knowledge can at least be categorised to make sure that all necessary areas of knowledge are served. Equally, skills can be identified, which are necessary to enable the pupil to transfer knowledge and cultivate him or herself in form of character-shaping and acquiring practical wisdom. And finally, when these fundamental skills are learned, the pupil has the active potential to gain enough Bildung through Selbstbildung [self-bildung; self-cultivation] to shape one's own life and one's own self. In fact, at this point one is already on the way to developing one's own art of living. It must 
also be said that there is no end to Bildung, same as to the art of living; it is a potentially lifelong process of personal growth.

A valid question to ask in this context is if it is necessary at all to change anything in current educational systems and settings to enable pupils to live a good and beautiful life. The answer is a solid 'yes and no'. Human beings are in general very adaptive and able to achieve all sorts of things under impossible circumstances; and the shape of most educational systems and societies are hardly impossible for living a good life. However, tweaks and improvements are always possible, and the rapid developments in the last 50 to 60 years, which involve huge changes in the living environment and the social setting for most people, call for a re-assessment of current educational systems, as well as current social beliefs and norms (Liebau, 1999, p. 5). Depending on one's ideology and the underlying values one has in mind while reviewing current educational systems, methods and contents of curricula, one will conclude with very different results.

The majority of today's reviewing processes have as underlying assumption that the educational system should contribute and strengthen the national economy and cater to the needs of businesses and industry. As argued above, this perspective is important for every society to take into account, but it is certainly not the only aspect of importance for educational systems. Therefore, a review of our underlying beliefs and values is in order: the question we should ask is "In which society do we want to live?" Philosophical concepts like the art of living can be of major importance for answering this question and, thus, are a good guideline for reassessing educational structures.

As has been pointed out earlier, this process might not result in a radical change of nations' curricula and schooling systems, but more likely propose a fine-tuning and in some cases a long overdue clear out. The fine-tuning will, for example, take into account life skills - other than reading, writing and maths - that are important for a good life and the wellbeing of human beings. It might also suggest a closer inter-connection between school subjects and contents to improve the relevance for the student's own life and one's immediate circumstances. However, an art of living approach cannot prescribe how and what should be taught, as one always needs to take into account the social and cultural environment and cater to the diversity of human beings in general, as argued above. Hence, a certain openness and flexibility would be beneficial for every educational interaction.

In terms of content that is deemed relevant for the development of an art of living, Schmid (2000a, p. 319-322) proposes six areas of learning: the human being as individual; the social human being; difficulties and burdens of human life; striving for fulfilment and meaning in life; religions, beliefs and cultures of humanity; and the personal shape of life and global prospects. It is certainly disputable if Schmid's list includes all important aspects of a human life circle, as he claims, but this list is at the very least a good starting point to explore this field. Undoubtedly, every human being has an individual component, an idea of one's own self and one's own identity ${ }^{5}$. This identity stays always in relationship to the

5Some postmodern positions might contest the existence of an individual's own self and an own identity; however, the experience of oneself as a distinct agent, who's own consciousness has stronger control over than over other agents cannot be denied. One can make one's own legs move if one wish to do so, but it is much 
external world, including objects, other individual's and also social and cultural norms, beliefs and hierarchies. A human life is marked by a multitude of challenges and everyday choices as well as burdens, beginning with the necessity for food, water and sleep, up to common needs like social acceptance and support, and, finally, external influences like unemployment; financial problems; death of friends or family members; and so on. As argued earlier (Teschers, 2011), striving for happiness and well-being is a strong motivational factor for human beings, and this strive is often accompanied by a search for fulfilment and meaning in life. Traditionally, this search for meaning in life is connected with spirituality, religion and other cultural beliefs, which vary greatly on a global scale. Finally, the life of every human being is taking shape over time: if one is shaping one's own life in an active way, or one is passively driven through society and external influences, is again up to the individual. Especially in most western societies, however, one's life and everyday experiences are not only influenced by one's immediate surroundings, but through global events as well. At the same time, we experience an increase of opportunities in a more and more globalised world, which is significant for an active shaping process of one's own life. The more difficult parts for educational practice are to fill these abstract areas of learning with content; give meaning to them; and identify which topics are part of which category or categories. Some of the more sizeable topics have been identified by Noddings (2005) like good relationships; parenting; prudent economic behaviour - for example, saving money or being careful with credit-cards; or being prepared for work as part of one's life.

The final question raised in this section concerns the impact such a change of focus in educational systems would have for individuals in particular and societies in general. An answer here is, again, very dependent on the social and cultural setting one is working in and the practical implementation of an art of living driven educational practice. However, a few assumptions can be made on the premise that the educational intervention is improving the ability of pupils to live a good and beautiful life. First of all, it is most likely that people who are better equipped to live a good and beautiful life have an increased average of individual happiness and contentment. Enduring happiness and positive emotion, on the other hand, contribute to higher resilience and better coping abilities (Seligman, 2010, p. 36). An increased level of tolerance and communal support is quite possible, especially if the development of prudence and practical wisdom is taken into account. As an art of living educational approach needs to be flexible to cater for individual differences, pupils need to learn how to help themselves and how to learn, what they need to know for the life they want to live. Therefore, they are well equipped for life-long learning processes and significant changes in their future living environment.

On a society level, a wider diversity of lifestyles and ways of living, or at least a broader acceptance for them, can be assumed. The development of prudence and practical wisdom might, through more tolerance and the care for others, lead to less crime, more communal support and maybe even more equality in and beyond society. It would be interesting to see,

harder to make someones else move, especially if he or she does not want to do so. However influenced the formation of one's self might be, in the end there is a distinction between oneself and others. 
if this development would also spread on a global scale. In any case, a more prudent use of ecological resources can be considered beneficial for one's each own long term best interest and, therefore, might lead to an overall more sustainable behaviour. Considering the speed of development in the last century, a wide spread implementation of an art of living education could have a significant influence on societies in one generation's time and would make an immediate contribution to people's individual well-being and good life. Political and social processes, however, make this timeframe seem quite ambitious.

\section{Conclusion}

It should have become apparent in the course of this paper that the art of living and the ability for students to lead a potentially good life is of high importance for education. The impact of such an education on society could only be hinted on above, but is potentially huge and might prove its value by improving the quality of life in current societies significantly. However, there are many more issues in this context that need to be addressed in future work. One would be the interaction of the individual, other people and society in general; another one is the ethical implications deriving from an art of living approach, including the question of equality and inequality. A point mentioned in the introduction is the question of choice and the multitude of opportunities people in modern societies have. Barry Schwartz (2004), in his book The Paradox of Choice, makes a strong argument that the sheer unlimited amount of options one has for every single choice one has to make is actually limiting our freedom instead of broadening it. He identifies shortcomings in our choice-making processes, as well as techniques to improve these. A critique of his work and its relevance for an art of living approach in education will have to be conducted as well.

It was also stated in the introduction that the practical questions of how, when and where to teach the art of living could not be answered in the scope of this paper. However, the major question, if it is possible at all to help students develop their own art of living through educational intervention, can now be answered positively. It even has been argued that an overall end of education could be to enable students to lead a good life of their own choosing as far as possible. An educational approach to the art of living on the basis of Schmid's concept "Lebenskunst" has been argued to be a good starting point for this end to come to pass.

\section{References}

Csikszentmihalyi, M. (2008). Flow: The psychology of optimal experience. New York, NY: Harper Perennial.

Dewey, J. (2001). Democracy and Education. Electronic Classics Series. Hazleton, PA: The Pennsylvania State University.

Feldman, F. (2004). Pleasure and the Good Life: concerning the nature, varieties and plausibility of hedonism. New York, NY: Clarendon.

Liebau, E. (1999). Erfahrung und Verantwortung. Werteerziehung als Pädagogik der Teilhabe. Weinheim ; München, Germany: JuventaVerlag. 
Nehamas, A. (1998). The art of living: Socratic reflections from Plato to Foucault. Berkeley, CA: University of California Press.

Noddings, N. (2005). Happiness and Education. Cambridge, UK: Cambridge University Press.

Nussbaum, M. C. (2001). The fragility of goodness : luck and ethics in Greek tragedy and philosophy. New York, NY: Cambridge University Press.

Peters, R. S. (1973). Authority, Responsibility and Education. New York, NY: Paul S. Eriksson, Inc.

Schmid, W. (2000a). Philosophie der Lebenskunst : Eine Grundlegung. Frankfurt, Germany: Suhrkamp.

Schmid, W. (2000b). Schönes Leben? : Eine Einführung in die Lebenskunst. Frankfurt, Germany: Suhrkamp.

Schwartz, B. (2004). The Paradox of Choice: why more is less. New York, NY: ECCO.

Seligman, M. E. (2010). Authentic Happiness: using the new positive psychology to realise your potential for lasting fulfillment. London, England: Nicholas Brealey Publishing.

Teschers, C. (2010). "Lebenskunst" - Schmid's Concept of the Art of Living. In PESA Conference Proceedings 2010 Perth, Australia: Philosophy of Education Society of Australasia. Retrieved from <http://www.pesa.org.au/>.

Teschers, C. (2011). The art of living and positive psychology in dialogue. In PESA Conference Proceedings 2011 Auckland, New Zealand: Philosophy of Education Society of Australasia. Retrieved from <http://www.pesa.org.au/>. 